FACULDADE DE CIÊNCIAS ECONÔMICAS DA UFRGS
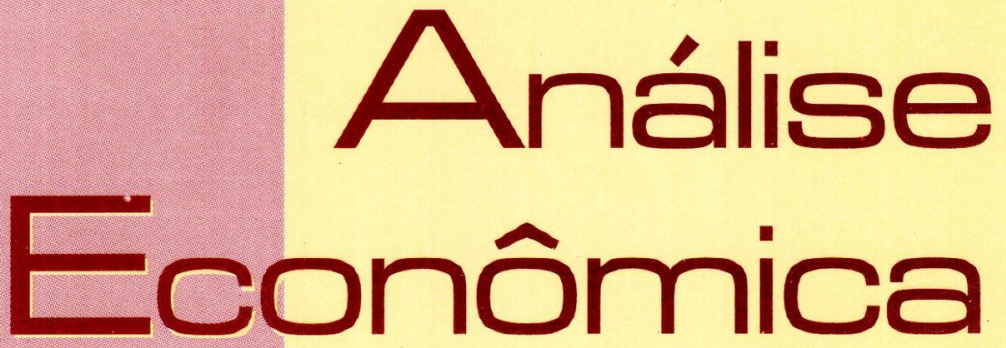

AS LOCOMOTIVAS ENFERRUIADAS

DO CAPITALISMO

Reinaldo Gonçalves

EFICIENNCIA, DESRECULAMENTACC̃O

FINANCEIRA E CRESCIMENTO

ECONOMICO: UMA ABORDAGEM

PÓS-KEYNESIANA

ROGÉRIO SOBREIRA

MERCADOS CONTESTÁVEIS E

COMPEIIÇÃO NO NOVO MODELO

DO SETOR ELÉtRICO BRASILEIRO

ELBIA VINHAES

EDVALDO SANTANa

MICROCRÉDITO: ASPECTOS TEÓRICOS

E EXPERIÊNCIAS

Márcio BobiK Braga

RUDINEI TONETO JR.

A RelaÇão Entre a Política e A ECONOMIA: SUAS IMPLICAÇÓES NO SISTEMA FINANCEIRO

JORGe PESSOA De MENDONĢA

AS RAiZzes CONCEITUAIS DO

INERCIALISMO

VAIDIR RAMAIHO

AUGE E INICIO DO DECLINIIO DA ECONOMIA ARGENTINA

maria Heló́sa lenz

$$
\text { ANO } \begin{array}{r}
18 \\
\text { No } 33
\end{array}
$$

MARÇO, 2000 
Universidade Federal do Rro Grande do Sui

Reitora: Prof ${ }^{a}$. Wrana Maria Panizzi

Faculdade de Ciências Econômicas

Diretora: Prof ${ }^{a}$ Otilia Beatriz Kroeff Carrion

Centro de Estudos e Pesquisas Econômicas

Diretor: Prof. Fernando Ferrari Filho

Departamento de Ciênctás Econòmicas

Chefe: Prof Luiz Alberto Oliveira Ribeiro de Miranda

Curso de Pós-Graduação em Economia

Coordenador: Prof. Marcelo Savino Portugal

Curso de Pós-Graduação em Economia Rural

Coordenador: Prof. Carlos Guilherme A. Mielitz Netto

Consel.ho Editorial:

Achyles B. Costa, Aray M. Feldens, Carlos A. Crusius, Carlos G. A. Mielitz Netto, Eduardo A. Maldonado Filho, Eduardo P. Ribeiro, Eugênio Lagemann, Fernando Ferrari Filho, Gentil Corazza, Marcelo S. Portugal, Nali I. Souza, Otnia B. K Carrion, Paulo A. Spohr, Paulo D. Waquil, Pedro C. D. Fonseca, Roberto C Moraes, Ronald Otto Hillbrecht, Stefano

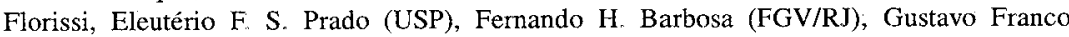
(PUC/RJ), João R. Sanson (UFSC), Joaquim P. Andrade (UnB), Juan H. Moldau (USP), Paul Davidson (Univ. of Tennessee), Werner Baer (Univ. of Illinois).

\section{Comissāo Entrorial:}

Eduardo Augusto Maldonado Filho, Fernando Ferrari Filho, Gentil Corazza, Marcelo Savino Portugal, Paulo Dabdab Waquil; Roberto Camps Moraes.

EorTor: Gentil Corazza

Edrror Adjunto: Pedro Silveira Bandeira

Secretário: Márcio Souza de Vargas

Revisão de Textos: Vanete Ricacheski

Fundador: Prof Antônio Carlos Santos Rosa

Os materiais publicados na revista Análise Econômica são da exclusiva responsabilidade dos autores. É permitida a reprodução total ou parcial dos trabalhos, desde que seja citada a fonte Aceita-se permuta com revistas congêneres. Aceitam-se, também, livros para divulgação, elaboração de resenhas e recensões. Toda correspondência, material para publicação (vide normas na terceira capa), assinaturas e permutas devem ser dirigidos ao seguinte destinatário:

PROF GENTIL CORAZZA

Revista Análise Econômica - Av. João Pessoa, 52

CEP 90040-000 PORTO ALEGRE - RS, BRASIL.

Telefones: (051) 316-3348 e 316-3440 - Fax: (051) 316-3990

E-mail: rae@vortex.ufrgs.br

Análise Econômica

Ano 18, $\mathrm{n}^{\circ} 33$, março, 2000 - Porto Alegre

Faculdade de Ciências Econômicas, UFRGS, 2000

Periodicidade semestral, março e setembro

1. Teoria Econômica - Desenvolvimento Regional -

Economia Agrícola - Pesquisa Teórica e Aplicada -

Periódicos. I. Brasil.

Faculdade de Ciências Econômicas,

Universidade Federal do Rio Grande do Sul. 


\title{
A relação entre a polífica e a economia: suas implicações no sistema financeiro
}

\author{
Jorge Pessoa de Mendonça*
}

Resumo: Este texto apresenta uma interpretação sobre a relação existente entre a economia e a política, em particular no aspecto financeiro. Tal relação é vista como inerente a cada uma dessas esferas, de modo a demonstrar a necessidade de incorporar os aspectos políticos na análise teórica das políticas econômicas e na interpretação do regime de acumulação em vigor.

Palavras-chave: Política econômica, finança, teoria da regulação.

\section{Introdução}

A finalidade deste texto é elucidar, sob um ponto de vista teórico, alguns aspectos sobre a relação entre a esfera econômica e a esfera política. No entanto, dada a abrangência do tema e as inúmeras implicações da teoria desenvolvida, concentrarei minha atenção no aspecto monetário e financeiro, embora, ainda que de forma genérica, pretenda ressaltar a importância política que a esfera financeira possui. Considerei que isto se deva fundamentalmente a duas razões. Primeiro, porque é através do tipo de financiamento e de crédito concedido ao Estado que a ordem econômica obtém condições para impor seus objetivos mais importantes. As condições de financiamento das contas públicas constitui um importante poder de pressão dos grupos econômicos mais fortes sobre o Estado. Segundo, porque a evolução monetária e financeira influencia bastante o comportamento das diversas classes sociais, na medida em que determina não só a distribuição e o tipo de alocação da riqueza, mas também o grau de legitimidade do regime político daí decorrente.

A abordagem que apresentamos difere claramente das interpretações correntes. Estas, mesmo quando consideram a interdependência existente, o fazem mais como uma restrição recíproca do que como resultado de uma relação de dependência entre as duas esferas. Tais análises são realizadas a partir

\footnotetext{
* Professor do Departamento de Economia da Universidade Federal do Espírito Santo e doutorando na Université Paris X - Nanterre.

Agradecemos a Heloisa Medina pelas sugestões apresentadas a uma versão preliminar, como também a Georges S. Rocha. Naturalmente é de responsabilidade do autor os erros ainda existentes.
} 
dos aspectos mais puros da lógica econômica ou da lógica política. ${ }^{1}$ Portanto, não explicitam realmente o que é constitutivo da relação em questão.

$O$ texto se desenvolve em cinco partes. A seção 2 consiste em algumas considerações sobre a questão metodológica. O objetivo é o de mostrar que, embora a teoria esteja apresentada num nivel teórico, seu desenvolvimento e aplicação estão intimamente ligados ao processo histórico. As seções 3 e 4 dicutem a importância das esferas econômica e política para o Estado, de modo a demonstrar como este último constitue o principal elemento para se analisar a relação em questão. A seção 5 centra atenção na dimensão política da esfera financeira, enquanto a seção 6 mostra as principais conseqüências desta abordagem teórica.

\section{Algumas considerações metodológicas}

A abordagem teórica apresentada não deve ser compreendida como um conjunto de definições independentes das situações concretas. Os conceitos desenvolvidos são considerados como um recurso metodológico, que permite apreender a realidade sempre em movimento. Assim, nós consideramos essas relações como inerentes à própria dinâmica do modo de produção capitalista, mais do que uma abstração justificável por sua aplicação ulterior. E essa dinâmica fornece a base da nossa interpretação, na medida da especificidade deste modo de produção e da multiplidade de aspectos que ele compreende.

É preciso considerar ainda que tais aspectos não são resultados unicamente da política ou da economia. Eles dizem respeito também a outros domínios, uma vez que a reprodução social depende necessariamente do tipo de estrutura social, das instituições e dos traços culturais existentes. A influência entre esses domínios e os fatores políticos e econômicos é recíproca. Sob um ponto de vista teórico, contudo, é legítimo realizar um corte. Pode-se reter apenas os aspectos políticos e econômicos, desde que a dinâmica do processo histórico esteja sempre presente. Assim, a analise se limitará a estes dois domínios sem negligenciar os demais. Na verdade, descrever os fenômenos sociais tendo como base sua própria reprodução exige a

\footnotetext{
' Estamos nos referindo principalmente aos trabalhos de Hayek, F. e Rawls, J., que constituem referência maior sobre esta questão, influenciando quase todas as análises sobre o assunto. O primeiro considerando a racionalidade econômica como a única capaz de garantir um desenvolvimento sócioeconômico satisfatório. O Estado ficaria limitado a assegurar a produção e distribuição de "bens comuns", como, por exemplo, a educação, mas ainda obedecendo a critérios exclusivamente econômicos O segundo, aceitando uma maior ingerência do Estado a fim de introduzir aspectos sociais e morais definidos pela esfera política, desde que sejam compativeis com o princípio de otimização de longo prazo da teoria econômica.
} 
inclusão, mesmo que implicitamente, de todos os aspectos que contribuem sobre tal processo. Além disso, a política e a economia não podem ser analisadas a partir de objetivos definidos ex-ante. Essas duas esferas estão em constante relação com a totalidade do processo, não se explicando pelo resultado previsto.

Sob o ponto de vista empírico, é inegável que a política se materializa necessariamente em instituições e se desenvolve segundo sua própria lógi$\mathrm{ca}^{2}$. O Estado se constitui como a expressão mais importante e acabada desta dimensão. Por conseguinte, as formas concretas do aparelho estatal, tais como os tributos e as despesas, comportam determinações políticas e institucionais importantes. Considerando que estas formas também estão diretamente ligadas à economia, elas constituem um espaço privilegiado para nosso estudo.

\section{A política e o Estado}

Segundo nosso ponto de vista, ao contrário das visões liberais, há uma distinção entre Política e Estado. A Política diz respeito à relação de forças que determina uma configuração específica de poder, enquanto o Estado se refere a uma forma particular de institucionalização do conjunto de relações sociais e econômicas. Além disso, consideramos não apenas as diferenças de conteúdo de cada um dos conceitos, mas também as conseqüências daí decorrentes. Assim se, por um lado, as questões políticas são reconhecidas por seu caráter recorrente, não se esgotando jamais no momento em que determinado resultado se produz, por outro lado, o Estado permanece garantia do modo de produção no qual se desenvolve a oposição entre os diversos interesses econômicos ${ }^{3}$. Desse modo, se uma crise política pode desembocar

\footnotetext{
${ }^{2}$ A este respeito 'Théret, B. declara: "Dado isto, nós podemos voltar ao conteúdo próprio da relação estatal e, para isso, nos colocar num nivel de análise onde seja possível considerar o Estado como um todo, ou melhor, como uma "abstração real" que se forma na realidade sob formas fenomênicas, tais como a constituição, o orçamento ou ainda o estatuto da função pública." (Théret, B., Régimes économiques de l'ordre politique, Presses Universitaires de France, 1992, p. 35) (tradução nossa)

${ }^{3}$ Esta maneira de apresentar o assunto corresponde ao desenvolvido por Poulantzas, N., que, após precisar a diferença entre crise política e crise de Estado, declara: "A crise política - crise do Estado mesmo possue, sob certos aspectos, um papel orgânico na reprodução da dominição de classe, já que a menos que o confronto leve a transformação para o socialismo, esta crise pode se mostrar a via (por vezes a única) para se restaurar por meios específicos e a "quente" uma hegemonia da classe dominante, e a via de uma transformação-adaptação do Estado capitalista às novas realidades da "lute de classes" [...] Pode-se, no entanto, manter este termo desde que sempre seja reservado à crise atual (estrutural), uma crise profunda que afeta o conjunto das relações sociais (crise política e crise econômica e que se manifestam numa conjuntura cujo conseqüêneia é o surgimento e a condensação das contradições inerentes à estrutura social." (Poulantzas, N., Crise capitaliste et politique économique sous la direction de Poulantzas, N., Presses Universitaires de France, 1976, p. 26).
} 
numă crise dä esfera governamental, o caso inverso não é comum mesmo sendo possível. A crise, seja ela na política ou no Estado organizado, não significa necessariamente a derrocada deste último, nem é um sinal de debilidade do sistema político.

No que diz respeito à política, as crises não constituem uma perturbação do curso normal dos acontecimentos. Elas podem persistir muito tempo sem que isto implique ruptura. De fato, uma controvérsia política não desemboca necessariamente na hegemonia de um dos grupos, e mesmo quando este for o caso, posteriormente o grupo hegemônico será ameaçado pelo grupo dos perdedores, o que pode conduzir a uma crise política de importância maior ou menor. Esta situação de crise agrava-se quanto maior forem as contradições inerentes à estrutura social. O Estado não é, no entanto, estranho a tal contexto. Embora ocorrendo uma crise política, as instituições públicas podem ser suficientes para manter a coesão social, visto que a mesma depende muito de outros fatores. Desta maneira, o poder público continua a exercer seu papel. Em suma, as crise políticas não implicam uma crise da totalidade das instituições públicas, menos ainda de toda a sociedade. Considerar uma crise como sinal de uma crise geral do capitalismo, ou até de uma crise final, conduz freqüentemente a interpretações errôneas.

Se o Estado representa o modo de produção e assegura o desenvolvimento econômico e social, pode haver assim uma defasagem entre a configuração específica que ele possui num dado momento e as necessidades de reprodução do sistema econômico. E tal situação pode vir acompanhada ou não de uma crise política. No entanto, a crise do aparelho estatal se instala, estimulando mudanças na sua estrutura. E isto pode acontecer, mesmo se o contexto político for estável. O mesmo ocorrendo, em maior ou menor grau, com o restante do aparato institucional existente. Este tanto pode evoluir para acompanhar as mudanças observadas na esfera governamental, quanto se constituir num meio de estimular tais mudanças. De fato, embora o Estado expresse o resultado de um processo político, ele deve ser comprendido como parte integrante do próprio processo. A dinâmica social interage com o Estado através do conjunto de instituições públicas e privadas, permitindo que os atores sociais e os diferentes segmentos econômicos traduzam seus objetivos como ação de governo ${ }^{4}$.

\footnotetext{
${ }^{4}$ Sobre este ponto é interessante a colocação de Jobert, B: “A distinção deste compromisso necessário entre a extração e a alocação de recursos permite interpretar em termos não funcionalistas o caráter intrinsicamente contraditório da ação política descrita anteriormente como sendo a arbitragem entre as exigências de regulação e de integração do sistema. Com efeito, não há porque interpretar estas exigências contraditórias em função de uma definição abstrata da ordem social. Elas encarnam, ao contrário, os laços de dependência multiformes dos poderes políticos em relação aos detentores de recursos." (Jobert, B., Les trois dimensions de la régulation politique. in L'Etat à l'épreuve du social. Sous la coordination de Auvergnon, P., Martin, P. et al, Edition Syllepse, Paris, 1998, p. 33) (nossa tradução).
} 
Desse ponto de vista, o Estado é considerado, sobretudo, como uma relação, no interior da qual o aspecto político é fundamental e estreitamente ligado à reprodução econômica e social. Longe de ser um fenômeno esporádico, as modificações da sua estrutura fazem parte do processo histórico do capitalismo. As configurações específicas que o quadro institucional assume, em particular o estatal, refletem a forma como a ordem econômica se reproduz. Em certa medida, este quadro representa a dimensão política desta ordem em dado momento ${ }^{5}$.

No que diz respeito ao aspecto social, é importante ressaltar dois pontos principais. Em primeiro lugar, ele possui uma dimensão fundamental na formulação e no desenvolvimento das políticas públicas. Não só porque é a partir desta esfera que se assegura a legitimidade dos sucessivos governos, mas também porque tais políticas consistem em definir a forma de integração, em nivel setorial e microeconômico, dos diversos segmentos na totalidade do processo de reprodução sócio-econômico. Em segundo lugar, tais aspectos pressupõem mediadores sociais - um conjunto de instituições representativas e suficientemente desenvolvidas para que a ação empreendida pelo Estado obtenha bons resultados. (Obviamente estamos excluindo aos Estados autoritários).

Desse modo, no Estado capitalista, a política aparece como o mecanismo de realização dos interesses dos principais grupos e camadas sociais da sociedade. A economia adquire uma dimensão relativamente importante entre esses interesses, mas sem que outras dimensões ligadas aos aspectos sociológicos ou culturais desapareçam. O Estado capitalista se acha, portanto, não somente fracionado em classe capitalista e classe de trabalhadores, mas igualmente dividido no interior dessas frações e submetido a restrições ligadas aos aspectos mencionados acima. Ou seja, a disputa política é constitutiva do Estado. Assim sendo, este se fundamenta sobre a hegemonia da fração dominante da burguesia, sobre a possibilidade mesmo de mudança deste grupo hegemônico e sobre as reenvidicações sociais.

No que diz respeito especificamente à relação política-economia, uma primeira determinação aparece claramente. Trata-se do poder que a política confere à fração de classe que detém as melhores condições para a reprodução do sistema. Porém, este poder não engendra uma independência da esfera econômica. Esta é constantemente limitada pelo poder político. De

\footnotetext{
${ }^{5}$ Ressaltando a necessidade de compreender bem este movimento no nível conceitual Poulantzas, $\mathrm{N}$. escreve: "Seria preciso agora avançar uma proposição adicional: essa separação do Estado e da economia se transforma ela mesma, sem ser abolida, segundo os estágios e fases do capitalismo. Com efeito, o espaço e, portanto, o conteúdo dos conceitos respectivos do político e da economia se modificam ele mesmo, na medida precisamente em que ele constitue um modo de produção apresentando uma reprodução ampliada." (Poulantzas, N., op. cit p. 33) (nossa tradução).
} 
fäto, o conflito de clāss̄es, as divergências no seio dessas classes e a existência das reevindicações, que não provém da economia, implicam uma autonomia relativa da esfera estatal. $\mathrm{E}$ isto acontece na medida em que esta esfera integra o modo como se desenvolve a correlação de forças políticas, possuindo assim os meios de influenciar a via adotada.

\section{A economia e o Estado}

É importante frisar que a relação entre Estado, política e economia não se deve apenas aos interesses específicos de uma classe, ou de uma fração dela no interior da sociedade. Se, por um lado, a política tem de contemplar diversos interesses econômicos, por outro lado, a economia também depende da esfera política. No modo de produção capitalista, esta dependência se estabelece no momento em que as relações econômicas se realizam. Com efeito, a relação salarial, a gestão da moeda e a regulamentação do mercado pelo Estado constituem condições necessárias ao desenvolvimento das relações econômico-capitalistas. Desse modo, os aspectos políticos constituivos do Estado determinam não só a base do capitalismo, mas também seu desenvolvimento.

Portanto, as autoridades públicas possuem um papel essencial para a implementação e a gestão das atividades produtivas. Os resultados econômi cos estão vinculados ao modo de regulação política de uma sociedade, uma vez que eles estão constantemente sob a influência direta de decisões tomadas pela esfera política e, por conseguinte, determinados por inúmeros fatores. Não se trata de mera interferência nas leis do mercado ou, como comumente propalado, de uma distorção da lógica otimizadora em razão da falta de condições políticas para que as autoridades econômicas a façam ser respeitadas. $\mathrm{Na}$ verdade, boa parte das medidas econômicas são tomadas sem que se possa prever suas conseqüências mais importantes, pois a incerteza sobre os resultados possíveis é inerente ao capitalismo. O quadro institucional pode constituir um referencial importante para a tomada de decisões, mas não substitui, de forma alguma, a intervenção contínua das autoridades para corrigir os efeitos indesejados das medidas implementadas no momento anterior, ou criar condições que forneçam novos objetivos. A definição sobre o tipo de intervenção a ser realizada é resultante de um processo político de negociação e compreende a escolha entre diversos objetivos diferentes.

No que diz respeito à força de trabalho, a relação salarial compreende aspectos que não derivam da economia. $\mathrm{O}$ tipo de controle sobre os trabalhadores constitui um dos parâmetros utilizados para sua formulação e 
implementação. As possibilidades são, por conseguinte, inúmeras, de acordo com as diversas situações existentes e não se limitam a um só resultado possível. A maior ou menor intensidade desse controle depende do desenvolvimento político e social resultante do tipo de organização de trabalho adotado. Visto que a escolha inicial determina o desenvolvimento ulterior, a via efetivamente tomada inclui as evoluções politicamente desejadas, além dos fatores essencialmente econômicos. Até mesmo, o preço da mão-deobra, por exemplo, é determinado segundo princípios que não dependem exclusivamente de fatores econômicos. Os salários e as condições de trabalho variam segundo a corelação de forças entre o capital e o trabalho. Em suma, a componente política não só é importante, como ela pressupõe também a intermediação da esfera governamental.

Em relação à moeda, é evidente que a oferta de capital-dinheiro e a oferta de capital-material estão intimamente ligadas. A produção e a reprodução de valor dependem sempre da quantidade de trabalho materializado nas mercadorias. Porém, é também evidente que, num nível de abstração menos elevado, estas formas de valor se materializam sob as formas de capital industrial, comercial e bancário. Cada uma delas tem tendência a se autonomizar, dando origem a ciclos de reprodução próprios.

Em relação ao capital bancário, a distinção entre dinheiro como meio de circulação e dinheiro como meio de pagamento torna-se essencial. O primeiro é o dinheiro necessário para efetuar as transações correntes, transferência de renda, enquanto o segundo esta ligado às operações escalonadas no tempo e representam as transferências de capital. Grosso modo, o nível total de liquidez depende da evolução do capital de empréstimo e da quantidade de signos de valor, a saber a moeda. O capital financeiro torna-se tão mais importante quanto maior for a demanda de capital-dinheiro e a possibilidade de aplicação da riqueza, em títulos ou ações, por exemplo. E isto, dadas as condições de valorização do capital produtivo e a quantidade de moeda. $O$ crédito e o financiamento se desenvolvem à medida que o sistema bancário gera os meios de pagamento e, assim, as condições de desenvolvimento do capital-dinheiro propriamente dito.

O que nos interessa mais é o fato que a gestão da moeda por um emprestador em última instância, o Banco Central, se torna fundamental. Esta instituição possui ao mesmo tempo a função de assegurar o sistema através da moeda nacional e de controlar a expansão dos meios de pagamento, realizada pelos bancos comerciais. Ou seja, a emissão monetária deve, necessariamente, ser realizada pelo Estado e sua circulação tem de estar assegurada por lei. Isto porque a produção de meios de pagamento pelos bancos comerciais obedecem a critérios de rentabilidade. No entanto, a 
necessidade de liquidar periodicamente o saldo das transações coloca limites à expansão da moeda bancária. A manutenção da tutela do Estado sobre as atividades bancárias garante uma estabilidade para todo o sistema, visto que limita o poder de cada instituição. O papel dos bancos não pode ser exercido pelo poder público, isto porque a gestão macroeconômica da moeda compreende elementos que são contraditórios com os objetivos das instituições financeiras, consideradas individualmente ou em grupo. ${ }^{6}$

Resta ainda mencionar um domínio em que a participação da esfera política é fundamental. Trata-se da formação e do desenvolvimento do mercado. Na economia, as modalidades de concorrência em vigor dependem do papel exercido pelo Estado. De fato, só podemos entender a dimensão do mercado a partir do seu desenvolvimento político institucional. Ou seja, o mercado é uma construção institucional, realizada ao longo de um processo histórico, podendo apresentar configurações específicas de acordo com o tipo de evolução desejada pela sociedade e a correlação de forças políticas entre os diversos segmentos sociais. Portanto, considerar o resultado final desse processo como sendo "natural" à organização social é completamente equivocado. A importância da relação salarial para o regime fordista é um exemplo. Ela não se resume à questão do montante de salário, mas refere-se principalmente ao modo como as instituições interligaram entre si o consumo, a produção e a evolução da estrutura social, em particular a educação e o sistema previdenciário. Quando as contradições deste regime engendraram a impossibilidade de manter o mesmo ritmo de acumulação do capital, diversas mudanças foram postas em prática a partir de critérios e parâmetros políticos.

\section{A dimensão política do sistema financeiro}

A dimensão política da finança não decorre apenas da necessidade de um banco central acima dos bancos privados e, por conseguinte, de uma regulamentação monetária realizada freqüentemente a partir de objetivos políticos. A moeda é em si mesma portadora de aspectos que não provém da economia. A formação e o desenvolvimento institucional de um sistema financeiro qualquer não diz respeito à economia pura, como já mostramos. Além disso, o dinheiro e as formas monetárias em desenvolvimento (cartão de crédito, depósitos remunerados e toda uma gama de novos produtos financeiros) são desde o início também resultado de uma relação social. $O$

${ }^{6}$ A proposta de emissão e gestão de moeda de forma totalmente privada, como propõe Hayek, F. é portanto, um "non-sens". Ele não considera a tendência dos bancos mais importantes impor seus interesses, a custa de outras instituições financeiras e dos objetivos de toda a sociedade. 
sistema financeiro adquire assim um poder político a partir do simples fato de que o controle da moeda the permite reproduzir esta relação, de modo a definir seu desenvolvimento e seus principais beneficiários. Por um lado, a política se acha ligada à economia, graças à importância que ela possui para a organização econômica, e ao crédito que o sistema financeiro concede ao governo. Por outro lado, esta relação é reforçada pelas características inerentes à moeda, que, além do mais, permite aos bancos privados emissores a possibilidade de influenciar fortemente o desenvolvimento da relação social.

Esta abordagem implica dois tipos de argumentação diferentes, embora complementares entre si. A primeira diz respeito à gênese da moeda, o valor que ela representa enquanto uma das formas do capital. A segunda diz respeito à circulação da moeda e suas conseqüências para a sociedade. E isto na medida em que a propriedade desta forma de valor estabelece os vínculos sociais de uma determinada sociedade, definindo a posição relativa dos indivíduos e dos diversos grupos.

No que diz respeito ao primeiro aspecto, considerar a gênese da moeda no contexto da teoria do valor, como o faz Marx, implica de antemão a idéia que o capital não pode ser reduzido a sua dimensão econômica. Ele é apenas a forma aparente de expressão da mais-valia e supõe, portanto, um embate político entre os trabalhadores e os empresários. No entanto, o capital encombre esse aspecto. As relações de produção se exteriorizam de maneira a apresentar o trabalho excedente como o lucro do capital produtivo mais a taxa de juros devida ao detentor do capital financeiro. A forma mais acabada do capital, o capital financeiro, parece produzir o valor de modo independente do capital produtivo e comercial, surgindo como um objeto que confere a seu proprietário o direito a taxa de juros, considerada como renda que lhe é própria.

Além da base política sobre a qual se opera a reprodução do capital, este estado de coisas implica um enorme desenvolvimento das estruturas sociais. Ele permite um desenvolvimento material bem mais importante do que aquele dos modos de produção anteriores, no entanto, identificando o progresso social com o desenvolvimento econômico. Ou seja, qualquer que seja o julgamento moral que se faça sobre as conseqüências do capitalismo para as diversas classes sociais, boas ou ruins, as categorias sociais e políticas estão sempre presentes nos aspectos econômicos. $\mathrm{O}$ arcabouço institucional de cada sociedade incorpora esta interação.

Desse modo, pode-se dizer que o dinheiro traz consigo as contradições políticas do modo de produção capitalista, incluido o capital portador de juros. Esta dimensão não pode ser eliminada, qualquer que seja o progresso das formas econômicas. Isso porque se a moeda deriva da relação capital- 
trabalho, ela não constitue somente um instrumento de poder de uma classe sobre a outra, ou instrumento de pressão sobre o Estado por parte daqueles que dispõem de condições para lhe conceder crédito. A importância política da moeda vai além desses dois níveis, que indicam a função da moeda enquanto meio de exercício direto de poder entre o atores sociais. $\mathrm{Na}$ verdade, a circulação monetária revela a correlação de forças entre as classes sociais e no interior de cada uma destas classes.

Por paradoxal que pareça, a moeda apresenta-se assim como intermediária ao mesmo tempo entre os grupos sociais e entre os indivíduos que compõem cada classe social. Ela é comumente identificada seja como o equivalente geral, que implica o conflito de classe, seja como mero meio de troca, necessário à circulação dos bens de consumo. No entanto, este paradoxo desaparece quando consideramos o problema numa ótica mais ampla. De fato, mantendo sua origem como valor que se desenvolve a partir do trabalho, ela representa também o meio pelo qual os indivíduos exercem sua soberania, uns em relação aos outros. A moeda engendrá um processo contínuo de diferenciação-indiferenciação individual, e isto, tanto do ponto de vista econômico quanto do ponto de vista social. A definição de classe capitalista ou trabalhadora é resultado da indiferenciação de cada um, segundo a renda monetária ou o tipo de acesso ao crédito e ao financiamento que se disponha. Em contrapartida, os índivíduos se diferenciam segundo o padrão de consumo que alcaçam. Esta diferenciação produz-se no interior das classes, tornando difícil o emprego desse conceito no sentido estritamente econômico. De fato, a sociedade torna-se cada vez mais segmentada de acordo com os procedimentos ligados aos aspectos culturais e sociais.

A emissão e a circulação monetária afetam simultaneamente o modo de acumulação do capital e as relações pessoais. Além disso a moeda possue um aspecto social que reforça os aspectos políticos anteriormente expostos. O sistema bancário adquire poder na medida em que suas atividades definem não só o tipo de investimento, mas também o contexto no qual se desenvolvem o processo de diferenciação e indiferenciação no interior das classes sociais. Ou seja, as atividades econômicas e a evolução social dependem da quantidade e das condições de emissão de moeda, dos créditos e dos financiamentos.

Do ponto de vista político, a importância da moeda nos conduz a duas conclusões iniciais. Primeiramente, o fluxo monetário pode revelar um disfunção na natureza dos aspectos responsáveis pela coesão social, como é o caso dos períodos de hiperinflação. Este fenômeno seria uma espécie de enfraquecimento dos valores sociais fundamentais. Ele significa uma busca contínua de diferenciação individual a partir de variações crescentes do 
poder monetário que cada um adquire. Em segundo lugar, visto que ocorrem períodos de alta inflação, ou até mesmo hiperinflação, sem acarretar uma desagregação social maior, é razoável supor que a análise dos determinantes da circulação monetária revela uma estrutura política de base específica.

\section{A determinação recíproca da economia e da política}

Da mesma forma em que há um espaço econômico na política, existe também um espaço político na economia. A organização capitalista não pode abrir mão da esfera política, seja para sua própria formação ou por conta do desenvolvimento das formas concretas que ela assume. Em outros termos, se a esfera política confere às classes e às frações de classe econômica um poder político propriamente dito, como acabamos de expor, o inverso é igualmente verdadeiro. No entanto, esse poder não implica independência em nenhum momento. Da mesma forma que ocorre com a economia, cujo conflito de classes compreende também divergências interclasses, a classe política pode aparecer muito dividida. A diversidade de reivindicações assegura de fato um poder relativo aos mentores da política econômica, permitindo que a esfera política procure a via de desenvolvimento econômico que melhor the convenha.

Esta dupla determinação da relação entre a economia e a política se exprime principalmente pelo regime fiscal e financeiro. Se a ordem econômica tem necessidade de uma base institucional para assegurar a produção e a reprodução de valor, a ordem política tem necessidade dos recursos fornecidos pela economia, a fim de manter sua legitimidade e acumular poder. $\mathrm{O}$ crédito destinado às atividades políticas será tão maior quanto mais importante for o apoio governamental às atividades econômicas. Em contrapartida, o apoio econômico depende da estabilidade política que tais atividades proporcionam à sociedade. Ou seja, cada esfera tenta impor sua própria lógica, mas tendo como limite a necessidade de assegurar reciprocamente boas condições de desenvolvimento, sob risco de inviabilizar o apoio mútuo que constitue a base da relação em questão.

É preciso ainda ressaltar as conseqüências desta abordagem. Primeiro, não é necessário a diferenciação entre os objetivos políticos e econômicos. Com efeito, não somente o crescimento econômico cria boas condições para a dimensão política, mas ela faz igualmente parte dos objetivos desta última. Do mesmo modo, a economia considera a estabilidade política como uma das suas finalidades. Esta estabilidade podendo ser mais ou menos funda- 
mentada sobre o respeito às conquistas realizadas pelos trabalhadores ao longo da história. As situações concretas dependem da sociedade que se analisa. Deste ponto de vista, por exemplo, a Europa se distingue claramente do Brasil, na medida em que para este último o crescimento econômico é muito mais importante para a legitimidade política do que as questões sociais. De fato, nós supomos que, por esta razão, os aspectos relativos à pobreza e à precarização do emprego foram descartados do debate político brasileiro recente. Além disso, a estrutura social e cultural brasileira parece ser compatível com esta via de evolução.

Em segundo lugar, o esgotamento do regime de acumulação provoca um processo de reforma das instituições públicas, já que estas se mostram inadequadas para reconduzir a retomada do crescimento. Por outro lado, uma reestruturação econômica supõe um novo tipo de regulação estatal e, portanto, uma certa reestruturação do Estado. No entanto, as reformas necessárias não ocorre sem problemas. Em primeiro lugar, se a esfera pública exerce inegavelmente uma função importante para o processo de valorização do capital, ela não pode evitar que crises periódicas se instalem, uma vez que fazem parte da lógica de acumulação do capital. Em segundo lugar, os conflitos políticos são mais agudos durante esses períodos. Interesses diferentes das principais frações da classe capitalista ocasionam freqüentemente uma exacerbação da crise política, numa proporção tal que o resultado pode ser a implementação de medidas contraditórias. Nesse contexto, surgem dificuldades crescentes de financiamento do governo, levando a um enfraquecimento contínuo das instituições públicas.

Este enfraquecimento indica mais o meio pelo qual os grupos mais fortes tentam fazer com que seus objetivos prevaleçam do que uma impossibilidade de sair da crise. Ou seja, quando um grupo não chega a impor seus interesses, a crise tende a se prolongar. Embora ela possa se revelar cada vez mais profunda, nos momentos mais graves há uma tendência de se reproduzir uma recomposição das condições precedentes, sem que a saída da crise ocorra, seja a médio ou a longo prazo. Ou seja, uma crise da regulação política não leva necessariamente a economia a aceitar, dado o grau de deterioração do quadro vigente, a adoção de medidas contrárias aos interesses dos grupos mais poderosos, mesmo que estas possam criar um ciclo virtuoso de crescimento.

Enfim, a terceira consequiência desta abordagem refere-se à distinção entre as medidas de política econômica, no sentido técnico do termo, e as medidas que obedecem a finalidades políticas mais gerais e estratégicas. Visto a dupla característica da gestão da moeda e da força de trabalho, ora as medidas tomadas pelo governo se inscrevem como uma necessidade eco- 
nômica, ora representam uma política deliberada em favor de uma fração da classe capitalista. Visto que uma via política implica, para sua realização, uma sucessão de medidas técnicas, esta diferenciação é ainda mais difícil de realizar?.

Finalmente, embora as dificuldades da análise teórica para explicitar a relação entre as medidas econômicas e políticas, é preciso reafirmar sua importância. Se as diversas formas que a interdependência entre estes domínios assume não são percebidas diretamente no resultado final das análises mais correntes, é possível explicar a questão examinando o embate político ao longo de um período. $\mathrm{O}$ que pretendemos indicar é que muitas das dificuldades comumente apresentadas como eminentemente econômicas têm, na verdade, origem política. Esta dimensão é fundamental para a explicação e a elaboração das medidas econômicas, não podendo ser apreendidas adequadamente pelas abordagens teóricas ortodoxas.

\section{Referências bibliográficas}

AGLIETTA, M et Orlean, A., La violence de la monnaie. Paris, PUF, 1982.

BÉLORGEY, J. M., "La répresentation de l'intérêt général en question". in L'Etat à l'épreuve du social. Sous la coordination de Auvergnon, P., Martin, P. et alli, Edition Syllepse, Paris, 1998.

BRUNHOFF, S., "Crise capitaliste et politique économique". in La crise de l'Etat., sous la direction de Poulantzas, N., Presses Universitaires de France, 1976.

FOURQUET, F。 et Murad, N. Valeur des services collectifs sociaux: une contribution à la théorie social. Association de recherche economiques et sociales, IKERKA, janvier, 1992.

HAYEK, F. Droit, législation et liberté. L'ordre politique d'un peuple libre, Presses Universitaires de France, 1993.

JOBERT, B. et Miller, P., L'Etat en action. Presses Univerisitaires de France, Paris, 1987.

JOBERT, B., "Les trois dimensions de la régulation politique". in L'Etat à l'épreuve du social. Sous la coordination de Auvergnon, P., Martin, P. et alli, Edition Syllepse, Paris, 1998.

LUKÁCS, G., Ontologia do ser social: Os principios ontológicos fundamentais de Marx. Editora de ciências humanas, São Paulo, 1979.

\footnotetext{
${ }^{7}$ Sobre esta questão Brunhoff, S. escreve: "Segundo o caso, o elo entre a medida monetária tomada e o contexto do conjunto não é o mesmo. Se ocorre sanção de modo estratégico, a política econômica passa por ser política monetária, ela mesma determinada pela política geral. Se há técnica de gestão monetária, esta aparece como um palitivo dentre outros; ela remete a uma política geral, que não assume como tal. É apenas no primeiro caso que a política econômica é a continuação da política por outros meios." (Brunhoff, S., Crise capitaliste et politique économique. Deuxième partie: crise économique et crise de l'Etat. sous la direction de N. Poulantzas, Presse Universitaire de France, 1976, p. 145, 46) (nossa tradução).
} 
POULANTZAS, N., Crise capitaliste et politique économique: sous la direction de Poulantzas, N., Presses Universitaires de France, 1976.

POULANTZAS, N., Hier et aujourd'hui : texte sur l'Etat. François Maspero, Repères, Paris, 1980.

RAWLS, J., Théorie de la justice. Editions du Seuil, 1987.

THÉRET, B., Régimes économiques de l'ordre politique, Presses Universitaires de France, 1992. 